\title{
The health of the nation
}

\author{
Seize the opportunity
}

Will the government's white paper The Health of the Nation (p 135) $)^{12}$ turn out to be the most important measure for improving the health of the English people since the birth of the NHS or just so much hot air? Following strong leads from the World Health Organisation, ${ }^{3+}$ it sets out an ambitious programme for shifting the focus of the health service from sickness to health. Target setting - as proposed by the white paper-is becoming an increasingly popular way of improving a population's health. ${ }^{5-14}$

This remarkable turnaround is a huge step forward for Britain's health policy, ${ }^{15}$ even though it is light on other accepted principles of the WHO's health for all movementsuch as engaging the full participation of the community and reducing inequalities in health. Success will require great effort, resources, and cooperation among professionals unused to working together in the requisite alliances. ${ }^{16}$ The conviction with which the government and the NHS Management Executive are planning to implement the white paper is therefore welcome. Despite the many obstacles on the long haul ahead it would be a tragedy if the initiative failed.

One danger will be making the five key areas and their targets ends in themselves. ${ }^{17}$ Any choice of targets may be faulted, but this first list is as good as any other. Starting with only a few priorities means that there will be scope to add more locally. Other national priorities will be added later, benefiting from the experience of the first phase. Quibbling at this stage will be unhelpful; the targets are only a means to an end, and it is the process of implementing them that will count.

Like most of its predecessors, the white paper emphasises the need for health promotion and health education, underlines the role of primary care, and calls for the close collaboration of the many agencies whose actions affect health. But there remains a disconcerting belief that much of the improvement will come about by exhorting individual people to live more healthily. It is crucial that social and economic policies are changed to allow people to choose the healthy options. ${ }^{18}$ The whole endeavour has been jeopardised by playing down the effects on health of, for example, poverty, unemployment, and homelessness. The new ministerial committee to coordinate the strategy and the decision to appraise the government's policies for their impact on health are steps in the right direction, but such initiatives will not remain credible if they ignore overwhelming scientific evidence on important influences on health. That lesson should be clear from the furore over the government's reluctance to ban tobacco advertising; the troops will in- evitably resent the call to fight lung cancer and heart disease while the generals are giving the ammunition to the enemy.

Despite the recognition that many more things than health care affect health, giving the NHS the lead role in implementing The Health of the Nation was logical. This, however, is both the best and the worst of times for the NHS to take on such responsibility. Since the recent reforms health authorities have been obliged to purchase services by assessing the maximum potential benefit to the population's health. ${ }^{19}$ Although this gives them the unprecedented ability to shape services to meet needs, the unleashing of market forces may also introduce a competitive tendency to restrict the flow of information. The result may be to limit the collaborative dialogue between workers in primary care, community care, and the hospital sector-those who most need to work together to improve the public health. The new market, however, will permit some radical rethinking about purchasing health enhancing services from agencies outside the NHS.

The reforms have greatly strengthened managerial accountability in the NHS. Managers will now have to meet objectives to improve health as well as to deliver care, making it harder for the urgent to overwhelm the important. The danger is that this may be misinterpreted after the recent turmoil of the reforms as yet another diktat imposed without sufficient resources on an overburdened health service, a view that will be enhanced by heavy handed managerial methods. The worrying tendency towards central directives reflects the white paper's failure to acknowledge the WHO's health for all principle of encouraging people to participate in decisions rather than telling them what to do. Too much top heavy management from the centre may kill the initiative by failing to engender genuine commitment to the new ideals required of clinicians, managers, and others in the front line. On the other hand, the centre will have a crucial role in constantly clarifying and reinforcing the changes needed to enable health professionals to make the most of their own skill in achieving the health targets. Such help might take several forms, including active support, education in the new ways of working, and adequate resources for the job.

Above all, the strategy requires a substantial programme of research and development. The last thing we need is to waste resources on poorly evaluated measures of dubious effectiveness. We simply do not have enough evidence yet about how to achieve much of what is expected. The business of local target setting is in its infancy, as is our knowledge of the political and organisational skills necessary to reach them ${ }^{20}$; we lack key epidemiological information and operational 
research. Moreover, many of the questions require progress in research methodology before the research itself can start.

None of this, however, will change anything much unless there is the political will to grasp the nettles of central government policy that affect health. The greatest potential of the white paper is that it could force the government's hand. The white paper is an unparalleled chance to make the NHS reforms work in the interests of the people's health. As health professionals we should seize this opportunity.

Professor of Public Health Medicine,

JOHN GABBAY

University of Southampton,

Wessex Institute of Public Health Medicine,

Winchester $\mathrm{SO} 225 \mathrm{DH}$

Secretary of State for Health. The health of the nation: a strategy for health in England. London HMSO, 1992. (Cm 1986.)

2 Delamothe T. Towards a healthier England. BMF 1992;305:135.

3 World Health Organisation. Alma Ata 1978. Primary health care. Geneva: WHO, 1978

4 World Health Organisation. Global strategy for health for all by the year 2000. Geneva: WHO, 1981.
5 Catford JC. Health targets. BMF 1991:302:980-1.

6 Lalonde M. A new perspective on the health of Canadians. Ottowa: Minister of Supply and Services, 1974.

US Public Health Service. Healthy people. Surgeon general's report on health promotion and disease prevention. Washington, DC: US Department of Health and Human Services, 1979.

8 Welsh Health Planning Forum. Strategic intent and directions for the NHS in Wales. Cardiff: Welsh Office, NHS Directorate, 1989.

9 New Zealand Government. A new relationship (includes New Zealand health goals and targets, health charter, and a contract for area health boards). Wellington: New Zealand Government Printing, 1989.

10 Northern Ireland Health Promotion Agency. Health promotion in Northern Ireland. A discussion paper. Belfast: Northern Ireland Health Promotion Agency, 1990.

11 Scottish Home and Health Department. Health education in Scotland - a national policy statement. Edinburgh: HMSO, 1991.

12 McGinnis JM. Setting objectives for public health in the 1990s: experience and prospects. Ann Rev Public Health 1990;11:231-49.

13 Jacobson B, Smith A, Whitehead M. The nations' health-a strategy for the 1990s. London: King Edward's Hospital Fund for London, 1991. (Revised ed.)

14 Faculty of Public Health Medicine of Royal College of Physicians. UK levels of health. London: Faculty of Public Health Medicine, 1991

15 Ashton J. The health of the nation. BMF 1991;302:1413-4.

16 Ashton J, Seymour H. The new public health. Milton Keynes: Open University Press, 1988.

17 Smith R. First steps towards a strategy for health. In: Smith R, ed. Health of the nation: the BMJ view. London: BMA, 1991

18 Research Unit in Health and Behavioural Change. Changing the public health. Chichester: John Wiley, 1989.

19 Stevens AJ, Gabbay J. "Needs assessment needs assessment...." Health Trends 1991;23:20-3.

20 Gabbay J. "Inspiring, politicking, plotting, cajoling...." BMF 1988;297:992.

\section{What future for the regions?}

\section{Only a single agency makes sense}

As the NHS reforms move into their second year the key question is, how will the market be managed? Little competition occurred in 1991-2 because ministers wanted a smooth take off for the reforms with no disruption before the election. By managing the market tightly the NHS Management Executive and the regional health authorities ensured a steady state. With the election out of the way purchasers and providers are beginning to change where services are provided. This is most evident in London, where several hospitals have failed to attract the contracts they need to maintain existing levels of services. Not surprisingly, purchasers are switching contracts to cheaper providers, and the acute sector in London is bound to shrink.

Similar changes are likely to occur elsewhere. The logic behind the reforms is that competition should be used to channel resources to efficient providers who are responsive to patients' needs and demands. It follows that inefficient and unresponsive providers will lose resources and have to cut back their services. Although competition may improve efficiency, the danger of an unregulated market is that access and equity might suffer. This might happen if purchasing decisions result in patients having to travel further to receive treatment or if resources are allocated to acute services at the expense of services for people with chronic conditions. To avoid these risks, a balance has to be struck between the incentives of the market and the need to take a strategic view of the distribution of health services. It is here that the role of regions is crucial. Ministers cannot manage the market directly from Whitehall - they must rely on an intermediate tier of management to oversee the activities of purchasers and providers and to deal with the consequences of failure of the market.

But what will this intermediate tier look like? As things stand, regional health authorities coexist with outposts of the NHS Management Executive, which were created last April to relate to NHS trusts on behalf of the management executive. The outposts were established partly because the management executive could not deal directly with the many trusts that came into existence in April and partly because trusts themselves did not want to relate to regional health authorities. In particular, many of those running trusts feared inappropriate controls by authorities perceived to be stuck in $\vec{\infty}$ the rut of old style NHS management.

The creation of outposts marks a further stage in the rise to power of the management executive. In the past three years $\overrightarrow{0}$ the executive has become firmly established as the head office for the NHS within the Department of Health. As such it has been used by ministers as a key tool for implementing government policies. At the same time the management executive has sought to become more effectively integrated with the NHS, partly through appointing managers such as $\stackrel{\odot}{\perp}$ Duncan Nichol to senior posts in the executive and partly $\overrightarrow{\vec{\prime}}$ through a deliberate strategy of working closely with NHS staff on developing and implementing national policies.

In this context the decision to set up outposts could be seen to prefigure the future role of the intermediate tier. In the longer term, having one regional organisation relating to providers (outposts) and another to purchasers (regional health authorities) makes little sense. If a coherent regional agency is to be created one option would be to build up the role of the outposts to enable them to perform the functions that are best carried out at a regional level in future.

These functions include allocating budgets to purchasers; $\stackrel{\sim}{\sigma}$ monitoring the performance of purchasers and providers and $\frac{7}{0}$ holding them to account; acting as a vehicle for transmitting and implementing national policies; and reporting back to the centre on the impact of policies on the ground, thereby shaping the emergence of new policies. And, to return to the starting point, the intermediate tier will also have an important role in managing the market. It is this role that is the least developed and little thought through. At a minimum 0 it encompasses arbitrating in disputes between purchasers

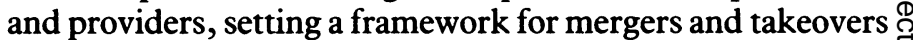
between purchasers and providers, taking a strategic view of $\stackrel{\AA}{\perp}$ health care needs and service developments, planning for education and research, and acting as the guardian of core 8 values - such as access and equity - as the market unfolds.

An alternative to building up the role of outposts would bec̄̄ to retain regional health authorities but to reduce their? number to bring them into line with the configuration of outposts and to limit their scope. In this way, the developing skill of the outposts in managing providers could be combined 